\title{
Flexible Simulation of an Electric Vehicle to Estimate the Impact of Thermal Comfort on the Energy Consumption
}

\author{
David Ramsey, Alain Bouscayrol, Member, IEEE, Loïc Boulon, Member, IEEE, Anatole Desreveaux, \\ and Alexandre Vaudrey
}

\begin{abstract}
The energy consumption of electric vehicles depends on the traction energy but also on the thermal comfort energy. Some studies lead to the estimation of this energy consumption from real measurements on different driving and climatic conditions. However, those results rely on a large number of vehicle tests, which is time consuming. Moreover, the impacts of the different subsystems cannot be differentiated in such global studies. A flexible simulation tool can help to analyze the impact of the different parts of a vehicle. This paper proposes a multiphysical parametrized model of an electric vehicle including the traction and comfort subsystems. A flexible model of a Renault Zoe is developed thanks to the energetic macroscopic representation. This model is validated by experimental tests of the real vehicle. Then, the impact of the HVAC (heating, ventilation, and air conditioning) subsystem is studied for different driving cycles and climatic conditions. In very cold conditions, the use of the HVAC subsystem represents an increase of up to $248 \%$ of the total energy consumption, compared to summer conditions.
\end{abstract}

Index Terms-air conditioning, cabin heating, climatic conditions, electric vehicle, energetic macroscopic representation, flexible simulation, HVAC system.

\section{NOMENCLATURE}

$\begin{array}{ll}\text { Main variables } & \\ \beta & \text { Recirculation ratio } \\ C & \text { Heat capacity }(\mathrm{J} / \mathrm{K}) \\ c_{p} & \text { Specific heat capacity at constant pressure }[\mathrm{J} /(\mathrm{kg}-\mathrm{K})] \\ \eta & \text { Efficiency of the powertrain }(\%) \\ F & \text { Force }(\mathrm{N}) \\ G & \text { Incident solar irradiance }\left(\mathrm{W} / \mathrm{m}^{2}\right) \\ i & \text { Current }(\mathrm{A}) \\ k_{d} & \text { Distribution input }(\text { for the strategies }) \\ M & \text { Mass of the vehicle }(\mathrm{kg}) \\ \dot{m} & \text { Mass flow rate of air }(\mathrm{kg} / \mathrm{s}) \\ \omega & \text { Humidity ratio }(\mathrm{kg} \text { vap } / \mathrm{kg} \text { da }) \\ O C V & \text { Open Circuit Voltage }(\mathrm{V}) \\ \dot{Q} & \text { Heat rate }(\mathrm{W}) \\ R & \text { Internal resistance }(\Omega) \\ \dot{S} & \text { Entropy flow }(\mathrm{W} / \mathrm{K}) \\ S o C & \text { State of Charge }(\%) \\ T & \text { Temperature }(\mathrm{K}) \\ u & \text { Voltage }(\mathrm{V})\end{array}$

Manuscript received October 14, 2021; revised December 17, 2021, and January 07, 2022; accepted January 08, 2022. (Corresponding author: D. Ramsey)

D. Ramsey, A. Bouscayrol and A. Desreveaux are with Univ. Lille, Arts et Metiers Institute of Technology, Centrale Lille, Junia, ULR 2697- L2EP, F-59000 Lille, France (e-mails: david.ramsey@univ-lille.fr; alain.bouscayrol@univ-lille.fr; anatole.desreveaux@univ-lille.fr).

$\begin{array}{ll}v & \text { Velocity of the vehicle (m/s) } \\ \dot{W} & \text { Electric power (W) } \\ \text { Subscripts } & \\ a m b & \text { Ambient air } \\ a n c & \text { Ancillaries } \\ b & \text { Battery } \\ b k & \text { Braking } \\ c a b & \text { Cabin (thermal node) } \\ c e i l & \text { Ceiling (thermal node) } \\ c o n d & \text { Conduction (heat transfer mechanism) } \\ c o n v & \text { Convection (heat transfer mechanism) } \\ c v & \text { Control volume } \\ d a & \text { Dry air } \\ e s & \text { External surfaces } \\ g & \text { Glass (for windows) (thermal node) } \\ h p & \text { Heat pump } \\ p a s s & \text { Passengers } \\ h v a c & \text { Heating, ventilation, and air conditioning } \\ i & \text { Each thermal node } \\ i m & \text { Interior masses (thermal node) } \\ i s & \text { Internal surfaces } \\ r a d & \text { Thermal radiation (heat transfer mechanism) } \\ r e c & \text { Recirculated } \\ r e f & \text { Reference (for control) } \\ r e s & \text { Driving resistances } \\ \text { sol } & \text { Absorbed solar irradiance } \\ t r a c & \text { Traction } \\ v a p & \text { Water vapor }\end{array}$

\section{INTRODUCTION}

B ATTERY electric vehicles (BEVs) represent a solution to reduce emissions of greenhouse gasses due to the transport sector [1]. However, their driving range, initial cost and long charging time limit their widespread adoption [2]. Although driving ranges have increased in recent years, they can still be strongly affected when considering the use of the HVAC subsystem for thermal comfort [3].

Recent research works on electrified vehicles have focused on their energy storage and management [4], [5], the development of charging infrastructure [6], the interaction with the power grid (V2G) [7], and the aging of their battery [8], [9]. Most of these works consider only the traction subsystem in

L. Boulon is with Institut de Recherche sur l'Hydrogène, Université du Québec à Trois-Rivières, Trois-Rivières, Québec, G9A 5H7, Canada (email: loic.boulon@uqtr.ca).

A. Vaudrey is with EIGSI La Rochelle, La Rochelle, France (e-mail: vaudrey@eigsi.fr). 
terms of energy consumption. However, the need for thermal comfort could entail a large variation of the overall energy consumption during the year, especially in regions with very cold winters [10]. This means that, for example, the performance of an energy management strategy, or the frequency of battery recharges would also vary during the year. Thus, the energy consumption of the HVAC subsystem should also be considered.

The impact of ambient conditions on the energy consumption has been studied under real driving conditions in [10], [12]. Results show reductions of $50 \%$ to $70 \%$ of the driving range under extreme cold conditions. Although the experimental approach highlights the overall impact of ambient conditions, the results are limited to the considered region and time of the study. Furthermore, they consider the combined effects of all factors related to the energy consumption (driving cycle, ambient conditions, desired cabin temperature, etc.), which may vary from one user to another. Finally, this approach requires a large amount of data, which is time consuming.

In contrast, numerical simulations, based on mathematical models, are flexible and enable repeatable and specific studies under various scenarios. Simulation is essential for the development and evaluation of new electrified vehicles [13]. However, an important modeling effort is required. In this context, a flexible simulation of a BEV in its environment will enable more complete studies on its performances under several scenarios and ambient conditions. For this, thermal models of the passenger cabin and the HVAC subsystem must be coupled with electrothermal models of the battery, and electromechanical models of the traction subsystem.

The traction subsystem has been widely studied in the literature [5]. Recent studies have focused on new powertrain architectures and control (e.g., four-wheel-independently actuated BEVs) [14], [15], on quantifying the overall energy consumption [16], [17], and on accurate driving range estimations [18]. A review of trends on electric powertrains can be found in [19]. Regarding the battery pack, several studies have addressed the impact of low temperatures on their performances, as well as their thermal management [20]-[22]. However, these studies have not considered thermal comfort.

Regarding the passenger cabin, the lumped-parameters approach has been used by [23]-[25] to model and validate the cabin of passenger cars, and by [26] for a minibus. This approach considers an average cabin temperature and the total heat flows at its boundaries. These models can describe accurately the evolution of the average cabin temperature under different ambient conditions. However, no interconnections with the models of the traction subsystem are presented.

Regarding the HVAC subsystem, the air ventilation circuit can be studied using classical air conditioning models [27], [28]. In addition, several studies have focused on the control and optimization of reversible heat pumps [29]-[31]. Some include simplified lumped-parameters models to also describe the evolution of the cabin temperature. However, these studies do not consider the large yearly variation of the cabin thermal needs, nor the reduced performances of heat pumps at very low temperatures. Moreover, experimental studies have analyzed the performances of heat pumps and electric heaters of electrified vehicles under extreme cold conditions [32]-[34]. In particular, Kim et al. [32] quantified the variation of the performance of a heat pump as a function of the ambient temperature. In these studies, no interconnections with the models of the traction subsystem are presented.

Finally, regarding the system interconnection, Neubauer et al. [35] from the National Renewable Energy Laboratory studied the performances of BEVs considering the ambient conditions of several cities in the United States, using an internally developed simulation tool. However, this study does not describe the modeling process, nor the experimental validations.

Despite the numerous existing models for the main subsystems of a BEV, an interconnection between them is rarely described. The development of a complete model is a challenging task, because it requires several complex models from different physical domains (i.e., thermal, electrical and mechanical), as well as their control and energy management (e.g., regenerative braking). Thus, an appropriate model organization is necessary. In this context, Horrein et al. [36] used the Energetic Macroscopic Representation (EMR) formalism [37] to develop a simplified model of the cabin and the electric heater of a hybrid electric vehicle and coupled it with the traction subsystem. This work studied the impact of electric heating on the energy consumption for mild winter scenarios. Likewise, German et al. [22] coupled an EMR-based electrothermal battery model with that of a traction subsystem to study the evolution of the battery temperature during driving (the comfort subsystem is not considered). The EMR formalism is based on a systemic modeling approach and organizes models according to their energetic function in the system, rather than their physical structure [38]. Thus, it considers the dynamic interactions between subsystems and facilitates the interconnection of multi-domain models into a unified simulator. In this paper, EMR is used to interconnect the models of the traction and comfort subsystem to develop a flexible simulation of a BEV.

Most simulation tools are based on a structural approach, where models strictly respect the physical topology of a system. These tools propose integrated libraries of predefined models, which facilitates the model interconnection for users. However, this approach could entail conflicts of association between variables, difficulties to modify the granularity of models and difficulties to define control schemes [38]. On the contrary, a functional organization of models (based on physical causality) leads to a prior solving of association conflicts. This enables seamless modifications of subsystem models and a systematic deduction of control schemes [37]. This functional-based simulation, organized through the EMR formalism, allows to estimate the energy consumption, and quantify the individual impacts of ambient conditions at a system and subsystem level. This flexibility is achieved by the unified organization approach, which allows to readily include, remove, or modify a model of a subsystem and adapt its control, without affecting the rest of the system.

The objective of this paper is to develop a flexible simulation 
of a BEV in its environment. This simulation tool will enable studies on the impact of thermal comfort on the energy consumption in various ambient conditions. The EMR formalism is used to organize and interconnect models of the main subsystems of a commercial BEV: a Renault Zoe (BEV of a French Automaker) [39]. The ambient conditions considered are ambient and sky temperatures, solar irradiance, and relative humidity. The accuracy of the simulation is verified by experimental tests on the real BEV. Finally, an energy consumption study is performed using real data of ambient conditions in a Canadian region. The main contributions of this paper are the interconnection and the experimental validation of multi-domain models of the passenger cabin, the HVAC subsystem and the traction subsystem of a BEV.

In a previous work, the traction subsystem of a Renault Zoe has been modeled and validated by driving tests on a real vehicle [17]. Moreover, an EMR-based model describing the interaction between the cabin and ambient air has also been developed and validated in [40]. The cabin model is now completed by considering the effects of solar and sky radiation. In addition, the model and control of an HVAC subsystem are included. Finally, all the models are interconnected.

Section II deals with the models of the BEV subsystems. In Section III, the simulation is validated by experimental measurements on a real BEV. Finally, the energy consumption of the thermal comfort subsystem is studied in Section IV.

\section{Modeling OF THE StUdied EleCtric Vehicle}

The studied vehicle (Fig. 1) is composed of a Li-ion battery, the traction and HVAC subsystems, and the rest of ancillaries.

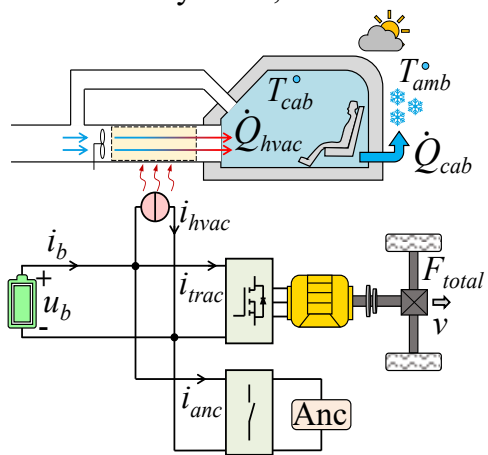

Fig. 1: Simplified structure of the studied BEV.

All models are organized and interconnected with EMR [37]. In EMR, all elements are represented by pictograms, according to their energetic behavior. Thus, regardless of their physical domain or their real structure, elements can only be depicted as energy sources (green ovals), energy accumulators (orange crossed rectangles), monodomain or multidomain energy converters (orange squares or circles), and energy distributors (overlapped orange squares or circles). This feature facilitates the organization and interconnection of models from complex multi-domain systems, as well as the development of their control structures. In addition, the interaction principle is considered by the 2 arrows connecting the pictograms. The product of the action and reaction variables always yields the instantaneous power being exchanged between elements. This feature facilitates the analysis of energy transfers within the system. By using the EMR formalism, a systemic approach is adopted [38]. Thus, the dynamic interactions between subsystems and with the environment of the vehicle are considered.

\section{A. Model of the traction subsystem}

The traction subsystem considers the battery, an electric drive, a mechanical transmission, the inertia of the vehicle and the rest of ancillaries. Since it has already been widely studied in the literature, a simplified quasi-static model is presented. Fig. 2 shows the EMR and control structure of this subsystem.

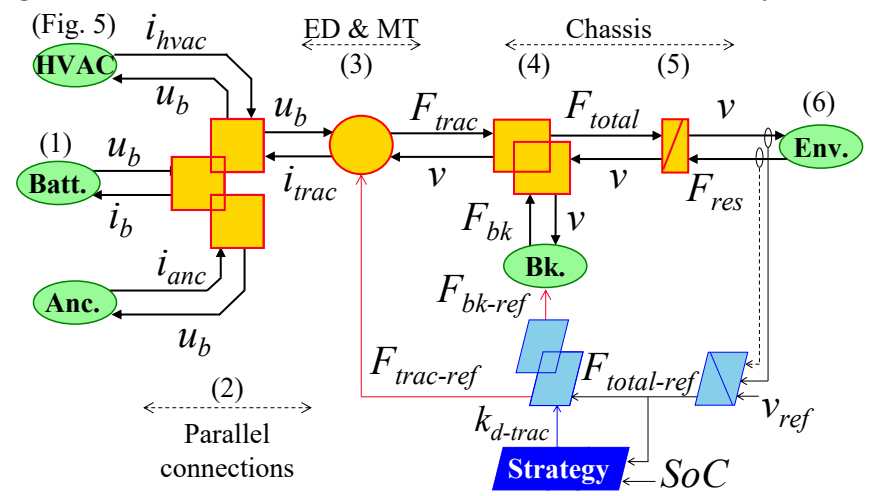

Fig. 2: EMR and inversion-based control of the traction subsystem.

The battery pack is depicted as an energy source imposing its terminal voltage $u_{b}$ to all the subsystems of the vehicle. This voltage is a function of the open-circuit voltage $O C V$, the state of charge $S o C$, the current $i_{b}$, and an equivalent internal resistance $R_{b}$. The current $i_{b}$ is the sum of those absorbed by each subsystem. The current $i_{\text {hvac }}$ is obtained from the model of the HVAC subsystem, and the current $i_{\text {anc }}$ is obtained by considering a constant power demand from the rest of ancillaries. These parallel connections are described by an energy distribution element. Since this study is focused on the thermal comfort, the temperature effects on the battery are not considered. However, an EMR-based electrothermal battery model has already been developed in [22] and will also be considered in future works

$u_{b}=O C V(S o C)-R_{b} i_{b}$

$i_{b}=i_{\text {trac }}+i_{\text {hvac }}+i_{\text {anc }}$

A static model describes the coupling of the electric drive (ED) and the mechanical transmission (MT) as a controlled electromechanical converter [41]. This converter imposes the traction force $F_{\text {trac }}$, which is equal to its reference. Moreover, the current $i_{\text {trac }}$ is obtained from $u_{b}, F_{\text {trac }}$, the velocity $\mathrm{v}$ and a global efficiency $\eta$. This global efficiency is based on the efficiency map of the electric drive of the Renault Zoe [42] and a constant efficiency for the mechanical transmission (Fig. 3).

$\left\{\begin{array}{l}i_{\text {trac }}=\frac{F_{\text {trac }} v}{u_{b} \eta k} \\ F_{\text {trac }}=F_{\text {trac-ref }}\end{array}, \quad\right.$ with $k=\operatorname{sign}\left(F_{\text {trac }} v\right)$

Mechanical brakes are depicted by a controlled energy source imposing the braking force $F_{b k}$. The total force acting on the vehicle $F_{\text {total }}$ is the sum of $F_{t r a c}$ and $F_{b k}$. 


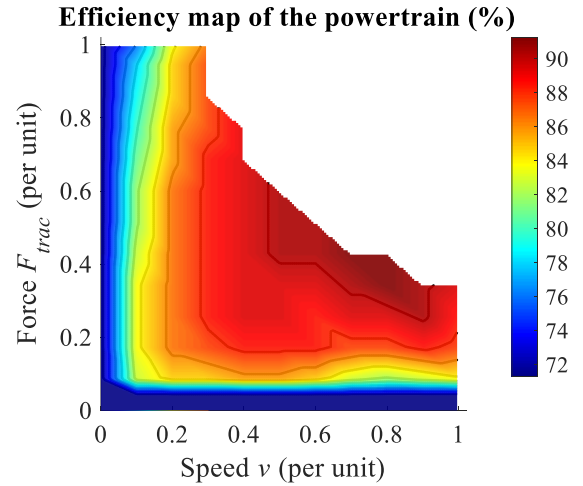

Fig. 3: Efficiency map considered for the electric powertrain.

$\left\{F_{\text {total }}=F_{\text {trac }}+F_{b k}\right.$

$\left\{F_{b k}=F_{b k-r e f}\right.$

The mechanical inertia of the vehicle is depicted as an energy accumulation element imposing its velocity $v$, which is obtained from the vehicle mass $M$, the total force $F_{\text {total }}$, and the driving resistance forces $F_{\text {res. }}$.

$\frac{d}{d t} v=\frac{1}{M}\left(F_{\text {total }}-F_{\text {res }}\right)$

Finally, the driving resistance force $F_{\text {res }}$ is the sum of the rolling resistance $F_{\text {roll }}$ and the aerodynamic drag $F_{\text {drag }}$ [5]. The force $F_{\text {drag }}$ is a function of the air density, and thus is also influenced by ambient conditions $\left(T_{a m b}\right.$ and $\left.\omega_{a m b}\right)$ [43].

$F_{\text {res }}=F_{\text {roll }}+F_{\text {drag }}\left(T_{\text {amb }}, \omega_{\text {amb }}\right)$

From the EMR, an inversion-based control is deduced. Moreover, a strategy imposes a coefficient $k_{d \text {-trac }}$ to distribute the braking effort during regenerative braking. The regenerative braking strategy considers the velocity, the braking effort distribution between both axles and the limits of the electric drive [5]. More details and the model validation using a real vehicle can be found in [17]. Classical studies consider this type of model to estimate the energy consumption of BEVs. Some studies consider a constant power for the HVAC consumption, others neglect it. The rest of this section presents the modeling of the passenger cabin and HVAC subsystems.

\section{B. Model of the passenger cabin}

The passenger cabin model is based on the lumpedparameters approach: each body is considered as an equivalent thermal node and temperature gradients are neglected [26]. Fig. 4 shows the structure of the passenger cabin and the HVAC subsystem. The considered heat rates are internal and external convection $\left(\dot{Q}_{c o n v}\right)$, thermal radiation between internal surfaces $\left(\dot{Q}_{r a d}\right)$, conduction through the roof $\left(\dot{Q}_{c o n d}\right)$, the heat produced by passengers $\left(\dot{Q}_{\text {pass }}\right)$, the heat supplied or removed by the HVAC subsystem $\left(\dot{Q}_{h v a c}\right)$, and solar $\left(\dot{Q}_{s o l-a b s}\right)$ and sky $\left(\dot{Q}_{r a d-s k y}\right)$ radiation. Moreover, all heat rates into the cabin are considered positive and heat transfers through doors and floor panels are neglected.

Since heat rates $\dot{Q}$ are already rates of energy transfers (power), the property entropy $S$ is included in the EMR-based modeling. Thus, entropy flows $\dot{S}$ at the boundaries of a body are a function of its temperature $T$ and the heat rates $\dot{Q}$.

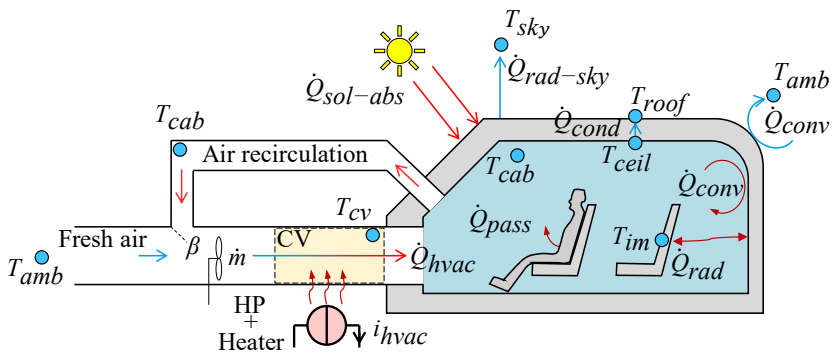

Fig. 4: Structure of the HVAC subsystem and the passenger cabin.

$\dot{S}=\frac{\dot{Q}}{T}$

The EMR of the passenger cabin is shown in Fig. 5. The considered thermal nodes (and temperatures) are the cabin air $\left(T_{c a b}\right)$, the equivalent interior masses (i.e., dashboard, seats, etc.) $\left(T_{i m}\right)$, the ceiling $\left(T_{\text {ceil }}\right)$, the roof $\left(T_{\text {roof }}\right)$, and the windows $\left(T_{g}\right)$. These nodes are represented as energy accumulation elements (orange crossed rectangle).

The temperature evolution of each node ( $i$ ) depends on their equivalent thermal capacity $C_{i}$, and the total entropy flows entering $\dot{S}_{i \text {-in }}$ and exiting $\dot{S}_{\text {i-out }}(8)$. These total entropy flows are obtained from entropy balances at the boundaries of each node (9) and are depicted as energy distribution elements (overlapped orange squares). Moreover, vector notation (i.e., square brackets) is used to denote the temperatures of all windows $\left[T_{g}\right]$, all internal surfaces $\left[T_{i s}\right]$, all external surfaces $\left[T_{e s}\right]$, and their corresponding entropy flows.

$T_{i}=T_{i_{0}} \exp \left(\frac{1}{C_{i}} \int\left(\dot{S}_{i-\text { in }}-\dot{S}_{\text {i-out }}\right) d t\right)$

$\left\{\dot{S}_{i-i n}=\sum \dot{S}_{i n}\right.$

$\left\{\dot{S}_{\text {i-out }}=\sum \dot{S}_{\text {out }}\right.$

Heat rates $\dot{Q}$ between 2 nodes at different temperatures ( $T_{\text {hot }}$ and $\left.T_{\text {cold }}\right)$ depend on the heat transfer mechanism: conduction $\dot{Q}_{\text {cond }}$, convection $\dot{Q}_{\text {conv }}$ or radiation $\dot{Q}_{\text {rad }}$ [27], and are depicted by monodomain energy conversion elements (orange squares). The equivalent entropy flows are then obtained from (7). More modeling details can be found in [40].

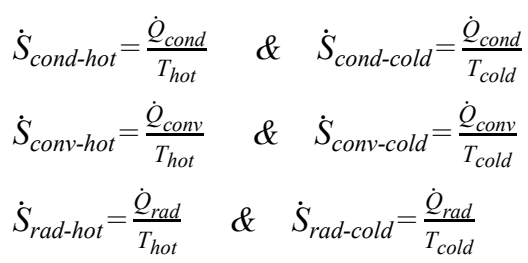

Passengers are considered as an energy source imposing their generated entropy flow $\dot{S}_{\text {pass }}$, which is obtained from their generated sensible $\dot{Q}_{\text {sensible }}$ and latent $\dot{Q}_{\text {latent }}$ heat rates [27].

$\dot{S}_{\text {pass }}=\frac{\dot{Q}_{\text {senible }}+\dot{Q}_{\text {latent }}}{T_{\text {cab }}}$

For the absorbed solar irradiance, the entropy flow $\dot{S}_{\text {sol- } i}$ depends on the total incident irradiance on each surface $G_{i}\left(W / \mathrm{m}^{2}\right)$, the surface area $A_{i}$, and the absorptivity of the material $\alpha_{i}$. For interior masses, the entropy flow also depends on the transmissivity of windows $\tau_{g}$. Solar irradiance (depicted 


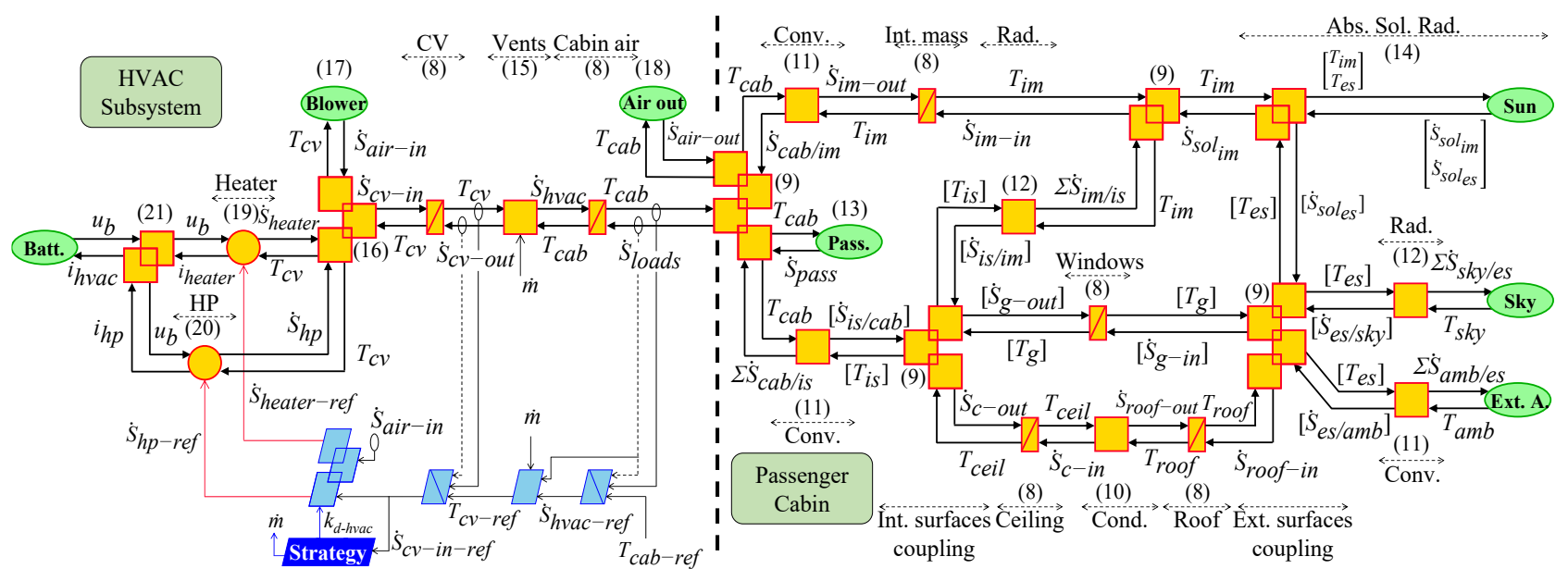

Fig. 5: EMR and inversion-based control of the HVAC subsystem and the passenger cabin.

as an energy source) can be either obtained from measures or estimated using an isotropic sky model, as described in [44].

$\left\{\begin{array}{l}\dot{S}_{\text {sol }_{i}}=\frac{\alpha_{i} G_{i} A_{i}}{T_{i}} \quad \text { for external surfaces } \\ \dot{S}_{\text {sol }_{i m}}=\alpha_{i m} \frac{\sum \tau_{g_{i}} G_{i} A_{i}}{T_{i m}} \text { for interior masses }\end{array}\right.$

Finally, ambient air and the sky are energy sources imposing their temperatures $T_{a m b}$ and $T_{s k y}$. Sky temperatures can be estimated from correlations described in [45] and [46].

\section{Model of the HVAC subsystem}

The HVAC subsystem (see Fig. 4) is composed of the air ducts, a recirculation flap, an air blower, the air vents and two heat sources: an electric heater and a reversible heat pump (HP). The reversible heat pump supplies heat during winter and absorbs it in summer.

To model this subsystem, a control volume (CV) is considered around the heat pump and the electric heater [28]. Thus, the blown air enters the cabin at a temperature $T_{c v}$. This approach is used to facilitate the control of the system and the experimental validation. Moreover, the condensation of water vapor in summer could represent an additional latent heat load on the heat pump [27]. This is considered by including the humidity ratios $\omega$ (ratio of the mass of water vapor to the mass of dry air) in the model. Humidity ratios are obtained from the ambient humidity, and from mass balances in the cabin and the control volume [27], [28].

The air vents are depicted by an energy conversion element. The heat flow leaving the control volume (and entering the cabin) $\dot{Q}_{h v a c}$ depends on the mass rate of blown air $\dot{\mathrm{m}}$, the humidity ratio in the control volume $\omega_{c v}$, the specific heat capacities of dry air $c_{p-d a}$ and water vapor $c_{p \text {-vap }}$ and the temperature $T_{c v}$ [27]. Only sea level pressure is considered. The corresponding entropy flows are obtained from (7).

$$
\left\{\begin{aligned}
\dot{Q}_{\text {hvac }}= & \dot{m}\left[c_{p-d a}\left(T_{c v}-273.15\right)\right. \\
& \left.+\omega_{c v}\left(2.5 e 6+c_{p-v a p}\left(T_{c v}-273.15\right)\right)\right] \\
\dot{S}_{\text {hvac }}= & \frac{\dot{Q}_{\text {hvac }}}{T_{c a b}} \quad \& \quad \dot{S}_{c v-o u t}=\frac{\dot{Q}_{\text {hvac }}}{T_{c v}}
\end{aligned}\right.
$$

The total entropy flow entering the control volume $\dot{S}_{c v-i n}$ is the sum of the entropy flow coming from the blown air $\dot{S}_{\text {air }-i n}$, and that generated by the electric heater $\dot{S}_{\text {heater }}$ and the reversible HP $\dot{S}_{h p}$. The control volume is depicted by an accumulation element imposing its temperature $T_{c v}$, also obtained from (8)

$\dot{S}_{c v-i n}=\dot{S}_{\text {air-in }}+\dot{S}_{\text {heater }}+\dot{S}_{h p}$

The net heat rate of blown air $\dot{Q}_{\text {air-in }}$ depends on that of fresh air $\dot{Q}_{\text {fresh }}$ and recirculated air $\dot{Q}_{\text {rec }}$. These rates depend on the mass rate $\dot{m}$, the recirculation ratio $\beta$, and the ambient and cabin temperatures $\left(T_{a m b}\right.$ and $\left.T_{c a b}\right)$ and humidity ratios $\left(\omega_{a m b}\right.$ and $\left.\omega_{c a b}\right)$.

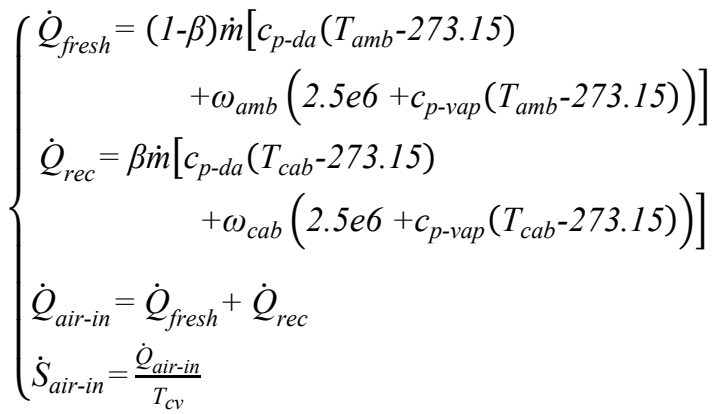

Likewise, the heat rate of the air leaving the vehicle $\dot{Q}_{\text {air-out }}$ when there is an input of fresh air depends on the recirculation ratio $\beta$, the mass rate $\dot{m}$, and the cabin conditions $T_{c a b}$ and $\omega_{c a b}$. It is assumed that the mass rate of air leaving is equal to that of the fresh air entering. The corresponding entropy flow $\dot{S}_{\text {air-out }}$ is obtained from (7).

$\left\{\begin{aligned} \dot{Q}_{\text {air-out }}= & (1-\beta) \dot{m}\left[c_{p-d a}\left(T_{c a b}-273.15\right)\right. \\ & \left.+\omega_{\text {cab }}\left(2.5 e 6+c_{p-v a p}\left(T_{c a b}-273.15\right)\right)\right] \\ \dot{S}_{\text {air-out }}= & \frac{Q_{\text {air-out }}}{T_{\text {cab }}}\end{aligned}\right.$

The electric heater is considered as a controlled electrothermal converter and is depicted by a multidomain energy conversion element (orange circle). Thus, the generated entropy flow $\dot{S}_{\text {heater }}$ equals its reference $\dot{S}_{\text {heater-ref. }}$ The consumed electric current $i_{\text {heater }}$ is obtained from $\dot{S}_{\text {heater }}$, the voltage $u_{b}$, and the temperature $T_{c v}$. 
$\left\{\begin{array}{l}\dot{S}_{\text {heater }}=\dot{S}_{\text {heater-ref }} \\ i_{\text {heater }}=\frac{\dot{S}_{\text {heater }} T_{c v}}{u_{b}}\end{array}\right.$

A static model also describes the reversible heat pump as a controlled electrothermal converter (multidomain energy conversion), with a Coefficient of Performance (COP). Thus, the generated entropy flow $\dot{S}_{h p}$ equals its reference $\dot{S}_{h p-r e f}$. The current $i_{h p}$ is obtained from $\dot{S}_{h p}$, the voltage $u_{b}$, the temperature $T_{c v}$, and the COP.

$\left\{\begin{array}{l}\dot{S}_{h p}=\dot{S}_{h p-r e f} \\ i_{h p}=\frac{\left|\dot{S}_{h p}\right| T_{c v}}{u_{b} C O P}\end{array}\right.$

The total current absorbed by the whole HVAC subsystem $i_{\text {hvac }}$ is the sum of $i_{\text {heater }}$ and $i_{h p}$. The power consumption of the blower is included with the rest of ancillary loads.

$i_{\text {hvac }}=i_{\text {heater }}+i_{\text {hp }}$

From the EMR (see Fig. 5), a control scheme can be obtained by direct inversion of each block between the objective variable (the cabin temperature $T_{c a b}$ ) and the control variables (the reference entropy flows $\dot{S}_{h p-r e f}$ and $\dot{S}_{\text {heater-ref). It should be noted }}$ that the presented control structure is ideal and quite different from that used in real automotive HVAC systems. Indeed, the control of a heat pump is much more complex, because it is necessary to regulate the pressures of the heat exchangers, as well as the mass flow of the refrigerant [29]. However, the presented approach suffices from an energetic standpoint, because it allows to estimate the amount of heat required to regulate the temperature of the passenger cabin. This is verified with the experimental tests presented in Section III.

To consider the performance limitations of heat pumps at low temperatures, the maximal generated entropy $\dot{S}_{h p}$ and the COP are limited according to the experimental results presented in [32]. Moreover, a strategy imposes a coefficient $k_{d-h v a c}$ to distribute the entropy flow generated by the heat pump and the electric heater. In this study, the heat pump is always prioritized. When it cannot supply all the heat needed in winter, the electric heater starts working. Further, the heat pump is considered to stop working at ambient temperatures below $-15^{\circ} \mathrm{C}$ [32]. Finally, a maximal heating power of $5 \mathrm{~kW}$ is considered for the electric heater.

\section{VALIDATION OF THE MODELS}

Three experimental tests have been performed on a commercial BEV, a Renault Zoe, to validate the developed models. The traction subsystem alone has already been validated experimentally in [17]. Regarding the parameters needed for the thermal models, the large majority have been obtained from previous studies [23], [26], [47], from tables of thermophysical properties for the materials used in automotive applications [27], [28], and from the datasheet of the Renault Zoe [39]. Table I shows the main parameters used in the simulation. Fig. 6 shows the equipment used during the validation tests.
TABLE I

MAIN VEHICLE PROPERTIES \& GEOMETRY

\begin{tabular}{|l|c|}
\hline Rated battery voltage & $350 \mathrm{~V}$ \\
\hline Rated energy storage & $41 \mathrm{kWh}$ \\
\hline Mass with 1 passenger & $1550 \mathrm{~kg}$ \\
\hline 12-V ancillaries and air blower power & $380 \mathrm{~W}$ \\
\hline Specific heat capacity of air & $1006 \mathrm{~J} /(\mathrm{kg}-\mathrm{K})$ \\
\hline Specific heat capacity of glass & $800 \mathrm{~J} /(\mathrm{kg}-\mathrm{K})$ \\
\hline Specific heat capacity of alluminum (roof) & $883 \mathrm{~J} /(\mathrm{kg}-\mathrm{K})$ \\
\hline Specific heat of capacity cotton (ceiling) & $1150 \mathrm{~J} / \mathrm{kg}-\mathrm{K})$ \\
\hline Equivalent heat capacity of interior mass & $100 \mathrm{~kJ} / \mathrm{K}$ \\
\hline Absorptivity of interior masses & 1 \\
\hline Absorptivity of the roof (white paint) & 0.26 \\
\hline Absorptivity of windows & 0.32 \\
\hline Transmissivity of windows & 0.5 \\
\hline Cabin volume & $2.5 \mathrm{~m}^{3}$ \\
\hline Interior mass area & $6 \mathrm{~m}^{2}$ \\
\hline Windshield area & $0.95 \mathrm{~m}^{2}$ \\
\hline Side windows area & $0.58 \mathrm{~m}^{2}$ \\
\hline Rear window area & $0.5 \mathrm{~m}^{2}$ \\
\hline Roof area & $2.17 \mathrm{~m}^{2}$ \\
\hline
\end{tabular}

a. Temperature datalogger

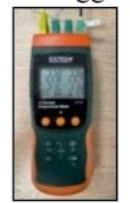

c. Air speed sensor

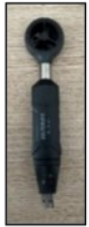

b. Solar irradiance datalogger

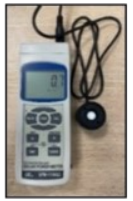

d. OBD Dongle (to acquire data from vehicle CAN network)
Fig. 6: Equipment used to measure data in validation tests.

The first test is performed to validate the passenger cabin model. In this test, the vehicle is parked outdoors for 10 hours. Solar irradiance, and the temperatures of the cabin and external air are recorded. Then, the same scenario is simulated, using the measured irradiance and external air temperature as inputs.

Fig. 7 a shows the measured solar irradiance. The variations after 13:00 are due to cloud movements. Fig. 7b shows that the evolution of the measured and simulated cabin temperatures are similar. The maximal absolute error is $3.5^{\circ} \mathrm{C}$ and the RMS error is $1.74{ }^{\circ} \mathrm{C}$. Thus, the accuracy of the cabin model is verified. An indoors validation of this model (neglecting solar irradiance) can be found in [40].

The second test is performed to validate the HVAC model and its control in cooling mode. For this, the vehicle is parked outdoors on a hot, partly cloudy day. The recorded measurements are solar irradiance, cabin and external air temperatures, and the air flow rate and temperature at the vents. The same scenario is simulated, using the measured irradiance, air flow rate and external air temperature as inputs. The desired cabin temperature is set to $21^{\circ} \mathrm{C}$.

Fig. 8 shows the validation results. Simulated and measured temperatures evolve similarly. The maximal absolute error for the cabin temperature is $\pm 3{ }^{\circ} \mathrm{C}$, during the transient state. During the steady state, the absolute error is less than $1{ }^{\circ} \mathrm{C}$. The 


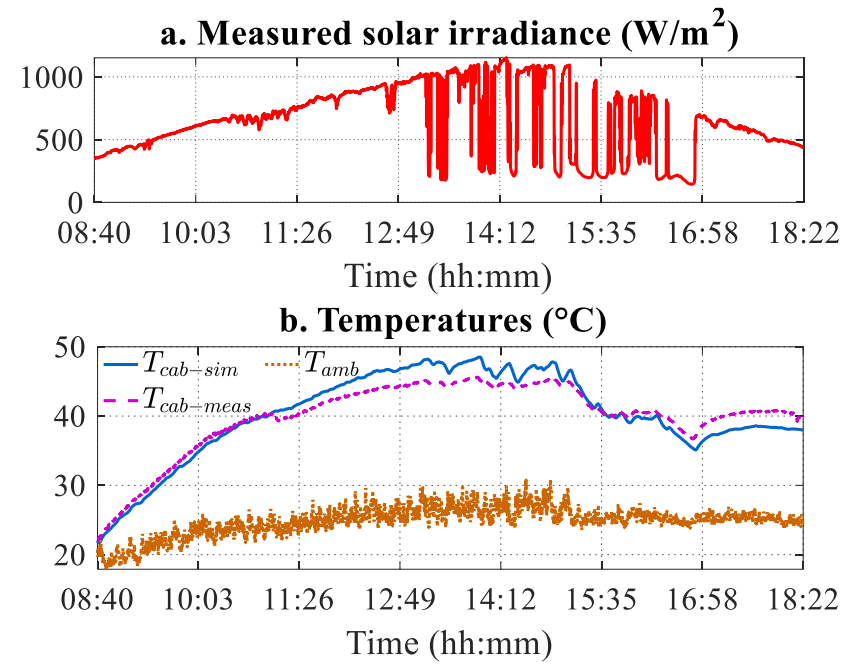

Fig. 7: Cabin model validation. a) Solar irradiance. b) Temperatures.

RMS error (considering the whole test) is $0.83{ }^{\circ} \mathrm{C}$.

To control the temperature of the cabin air, the HVAC subsystem acts upon the air flowing into the cabin $\left(T_{c v}\right.$ in the model). Thus, a good accuracy for both temperatures (cabin and vents) also means a good estimation of the cabin thermal needs and a good control of the HVAC subsystem. Therefore, the accuracy of the global model is verified.

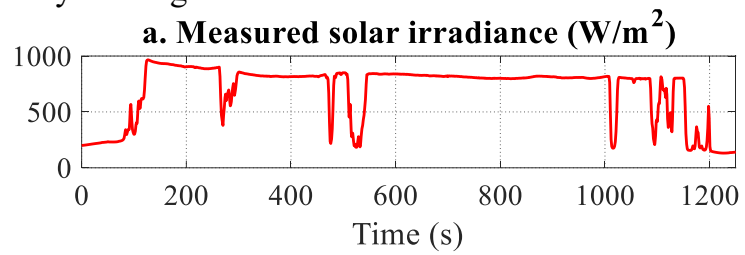

b. Temperatures $\left({ }^{\circ} \mathrm{C}\right)$

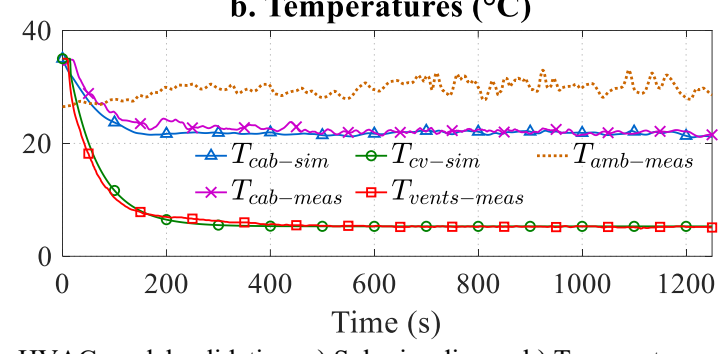

Fig. 8: HVAC model validation. a) Solar irradiance. b) Temperatures.

The third test is performed to validate the interconnection of the traction and passenger comfort models. In this test, the vehicle is driven on a cold morning $\left(T_{a m b} \approx-5{ }^{\circ} \mathrm{C}\right)$; thus, the HVAC subsystem is in heating mode. Ambient, cabin and vents temperatures, as well as the air flow rate are recorded. In addition, battery current and voltage measurements are extracted from the CAN network of the vehicle. The velocity is recorded with a GPS device. Measured solar irradiance at the time of the test was $\sim 100 \mathrm{~W} / \mathrm{m} 2$.

The same scenario is simulated, using the measured velocity, ambient conditions, and air flow rate as inputs. Fig. 9 shows the validation results. Simulated and measured temperatures, as well as the battery power evolve similarly. The error for the total energy consumption is $2.7 \%$. Thus, the interconnected model is also verified.

The presented experimental results firstly verify the accuracy of the model for the passenger cabin alone; then, of the coupling

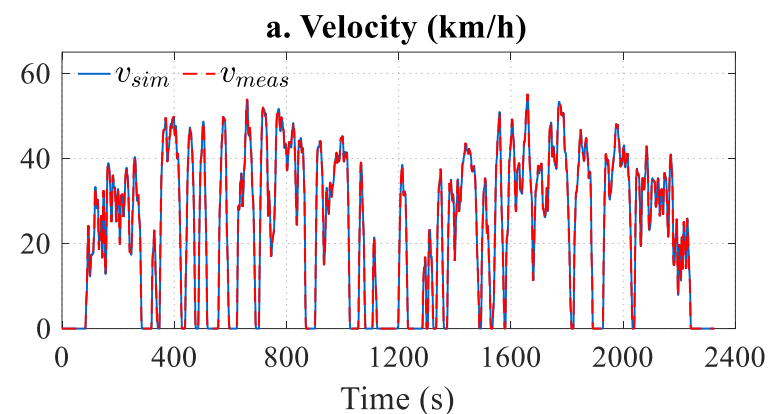

b. Temperatures $\left({ }^{\circ} \mathrm{C}\right)$

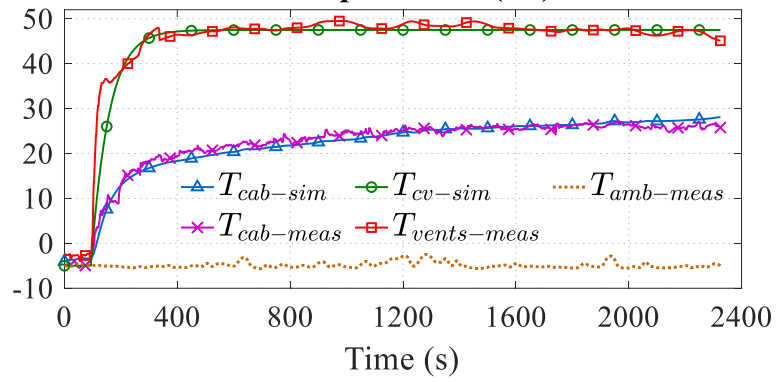

c. Battery power $(\mathrm{kW})$

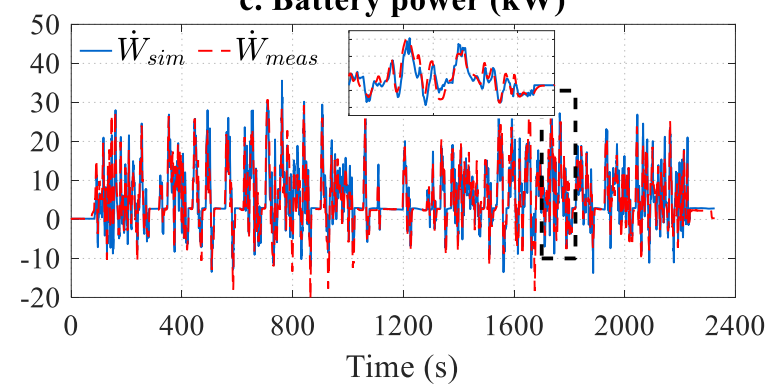

Fig. 9: Validation of the interconnected model. a) Velocity. b) Temperatures. c) Battery power.

of the passenger cabin with the HVAC subsystem and its control; finally, of the interconnection of the 3 subsystems. The considered tests include summer and winter scenarios, and all the results show that the simulated temperatures evolve similarly to the measured ones. Finally, the small error between the simulated and measured energy consumption for the last test (interconnected system), shows that the developed simulation can be used to estimate the energy consumption considering thermal comfort and real ambient conditions.

\section{VARIATION OF THE OVERALl ENERGy CONSUMPTION DUE TO THERMAL COMFORT}

The previous sections showed the development of an interconnected BEV model and its environment, as well as the validation tests. In this section, 2 energetic studies are performed. The first one is the contribution of the traction and HVAC subsystems to the overall energy consumption under different constant climatic scenarios. The second study is the yearly variation of the energy consumption using real data for ambient conditions in a cold region. For both studies, 3 types driving cycles are considered: urban, extra-urban and highway (the latter was obtained from real measures) (Fig. 10). 


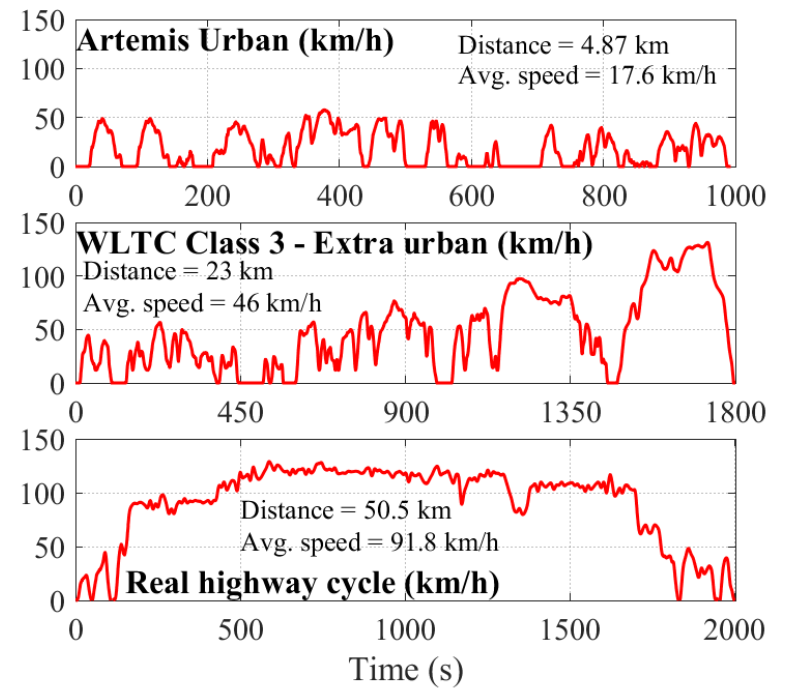

Fig. 10: Considered driving cycles.

\section{A. Distribution of the energy consumption per subsystem}

The first study is the estimation of the distribution of the energy consumption under different climatic scenarios (summarized in Table II). For all cases, the desired cabin temperature is $20^{\circ} \mathrm{C}$ and all initial temperatures are equal to the ambient temperature (no preconditioning). Finally, all simulations consider the same driving time (1 hour) to ensure the same consumption time for the HVAC subsystem.

TABLE II

CONSIDERED AMBIENT SCENARIOS (CONSTANTS)

\begin{tabular}{|c|c|c|c|}
\hline Scenario & Temperature & $\begin{array}{l}\text { Relative } \\
\text { humidity }\end{array}$ & $\begin{array}{c}\text { Sky } \\
\text { conditions }\end{array}$ \\
\hline Sc. 1 & $-20^{\circ} \mathrm{C}$ & $50 \%$ & Cloudy \\
\hline Sc. 2 & $-10^{\circ} \mathrm{C}$ & $50 \%$ & Cloudy \\
\hline Sc. 3 & $0^{\circ} \mathrm{C}$ & $50 \%$ & Cloudy \\
\hline Sc. 4 & $10^{\circ} \mathrm{C}$ & $50 \%$ & Cloudy \\
\hline Sc. 5 & $20^{\circ} \mathrm{C}$ & \multicolumn{2}{|c|}{ No thermal comfort (references) } \\
\hline Sc. 6 & $30^{\circ} \mathrm{C}$ & $50 \%$ & Clear \\
\hline Sc. 7 & $40{ }^{\circ} \mathrm{C}$ & $50 \%$ & Clear \\
\hline
\end{tabular}

Fig. 11 shows the results for the distribution of the total energy consumption for each considered case. As expected, the minimal energy consumption (for each driving cycle) is for scenario 5: $T_{a m b}=20^{\circ} \mathrm{C}$ and no HVAC. This scenario is taken as the reference. Thus, for each driving cycle, the variations of the energy consumption are calculated from the total energy consumption at each temperature (including the rest of ancillaries) and the energy consumption at $20^{\circ} \mathrm{C}$. As the climatic conditions change, the need for thermal comfort and the total energy consumption increase accordingly.

The results show that, besides climatic conditions, the impact of the HVAC subsystem on energy consumption strongly depends on the driving cycle. Urban cycles are characterized by short distances and a high number of stops (traffic lights, stop signs, etc.). This means that the HVAC subsystem and the rest of ancillaries continue to consume energy when the vehicle is not moving. This can result on a great increase of the overall energy consumption. For extreme cold scenarios, the HVAC subsystem can even become the main load on the battery.

Indeed, there is an inverse relationship between the energy
Energy consumption $(\mathrm{Wh} / \mathrm{km})$
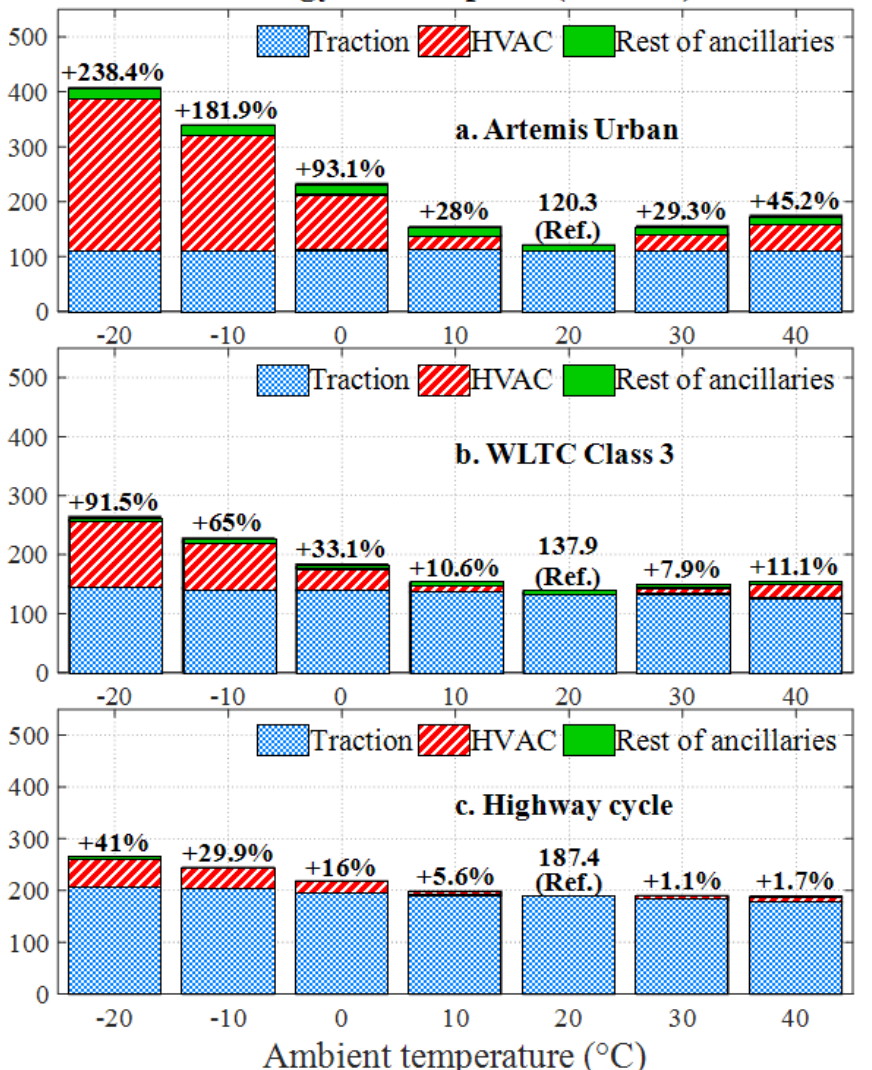

Fig. 11: Distribution of the energy consumption. a) Urban cycle. b) Extraurban cycle. c) Highway cycle.

consumption per kilometer of the traction and HVAC subsystems. Urban cycles have low average speeds and require low energy for traction. Thus, thermal comfort represents an important increase of total energy consumption (in Wh) over relatively short distances $(\mathrm{km})$. Moreover, the power required for traction and the distance traveled increase with the extraurban and highway cycles (over the same driving time). Therefore, the impact of thermal comfort on the energy consumption per kilometer (in $\mathrm{Wh} / \mathrm{km}$ ) decreases, whereas that of the traction subsystem increases. This concept is summarized in Table III, using the results for scenario $2\left(T_{a m b}=-10^{\circ} \mathrm{C}\right)$. This table shows that the total energy consumption (in Wh) of the traction subsystem increases from the urban cycle to the highway one, while that of the HVAC subsystem remains very similar. Since all simulations consider the same driving time, the average power and energy consumption of the HVAC subsystem is similar for all 3 driving cycles.

Thus, the impact of the HVAC subsystem on the overall energy consumption depends not only on climatic conditions, but also on the average speed of the driving cycle. As the average speed increases, the impact of the HVAC subsystem decreases. This allows for an analysis of the benefits of a passive driving style. Traditionally, a passive driving style, with smooth accelerations and low speeds, is considered more energy efficient. However, when the need for thermal comfort becomes important, a shorter driving time (and therefore higher speeds) can become advantageous from an energetic point of view. 
TABLE III

ENERGY CONSUMPTION OF THE TRACTION AND HVAC SUBSYSTEMS IN SCENARIO $2\left(T_{A M B}=-10^{\circ} \mathrm{C}\right)$

\begin{tabular}{|l|c|c|c|c|c|}
\hline For a 1-hour drive: & Urban & & Extra-urban & & Highway \\
\hline Distance (km) & 18.0 & $<$ & 46.5 & $<$ & 94.9 \\
\hline Traction energy (Wh) & 2032 & $<$ & 6640 & $<$ & 19056 \\
\hline HVAC energy (Wh) & 3785 & $\approx$ & 3664 & $\approx$ & 3767 \\
\hline $\begin{array}{l}\text { Traction energy per } \\
\text { kilometer (Wh/km) }\end{array}$ & 112.9 & $<$ & 142.8 & $<$ & 200.8 \\
\hline $\begin{array}{l}\text { HVAC energy per } \\
\text { kilometer (Wh/km) }\end{array}$ & 210.3 & $>$ & 78.8 & $>$ & 39.7 \\
\hline
\end{tabular}

B. Variation of the energy consumption with real ambient conditions

The second study is the yearly variation of the energy consumption with ambient conditions and the driving profile. For this, the climate of Regina (Canada) is considered. This region is chosen for its wide variation of ambient temperatures, which can range from $-30^{\circ} \mathrm{C}$ to $30^{\circ} \mathrm{C}$ over a year (Fig. 12).

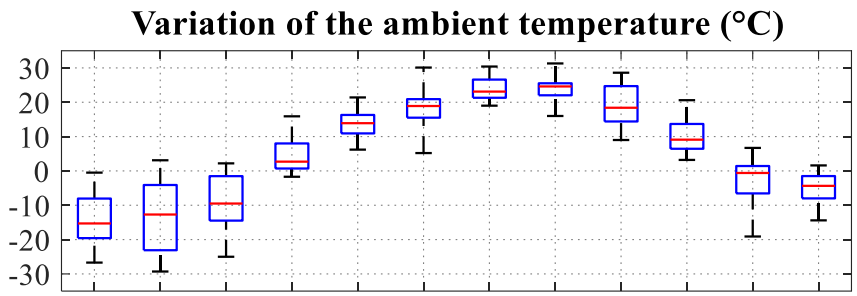

Jan Feb Mar Apr May Jun Jul Aug Sep Oct Nov Dec

Fig. 12: Monthly variation of the ambient temperature in Regina.

For this study, a simulation is performed for each day of the year at the same hour (11:00). Real data for ambient temperature and humidity, sky temperature and solar irradiance, obtained from [48], are used as inputs in the simulations. Moreover, the 3 driving cycles in Fig. 10 are considered. The desired cabin temperature is $20^{\circ} \mathrm{C}$ for all cases, except when ambient temperature is between $18{ }^{\circ} \mathrm{C}$ and $23{ }^{\circ} \mathrm{C}$ (no need for thermal comfort). All simulations consider one passenger and no preconditioning. The driving time is still 1 hour.

Fig. 13 presents the results of the simulations. First, we see that the energy consumption remains almost constant if only the traction subsystem is considered (classical energetic studies). In this case, the energy consumption just depends on the driving profile. For the highway profile, the slight increase at low temperatures is due to air density and the aerodynamic drag.

On the other hand, a large variation in consumption is obtained by considering the interconnection with the HVAC subsystem. In addition, we can still see that the impact of ambient conditions is much greater on the urban cycle. For this type of profile, the estimated energy consumption ranges from $120 \mathrm{Wh} / \mathrm{km}$ at $20{ }^{\circ} \mathrm{C}$, up to $418 \mathrm{Wh} / \mathrm{km}$ at very low temperatures: an increase of $248 \%$. For the extra-urban cycle, the overall energy consumption varies from $136 \mathrm{Wh} / \mathrm{km}$ at $20{ }^{\circ} \mathrm{C}$, up to $266 \mathrm{Wh} / \mathrm{km}$, an increase of $95 \%$. The highway cycle is the least impacted by the ambient conditions, with an increase in consumption of $43 \%$.

The results also show that a maximal value of the energy consumption is attained at very low ambient temperatures. As aforementioned, the developed model considers that the heat pump stops working when the ambient temperature drops below $-15{ }^{\circ} \mathrm{C}[32]$. At this point, only the electric heater is functional. However, the model also considers a maximal power of $5 \mathrm{~kW}$ for the electric heater. Thus, when the cabin thermal needs surpass this maximal heating power, the total energy consumption is capped by the maximal capacity of the HVAC subsystem.
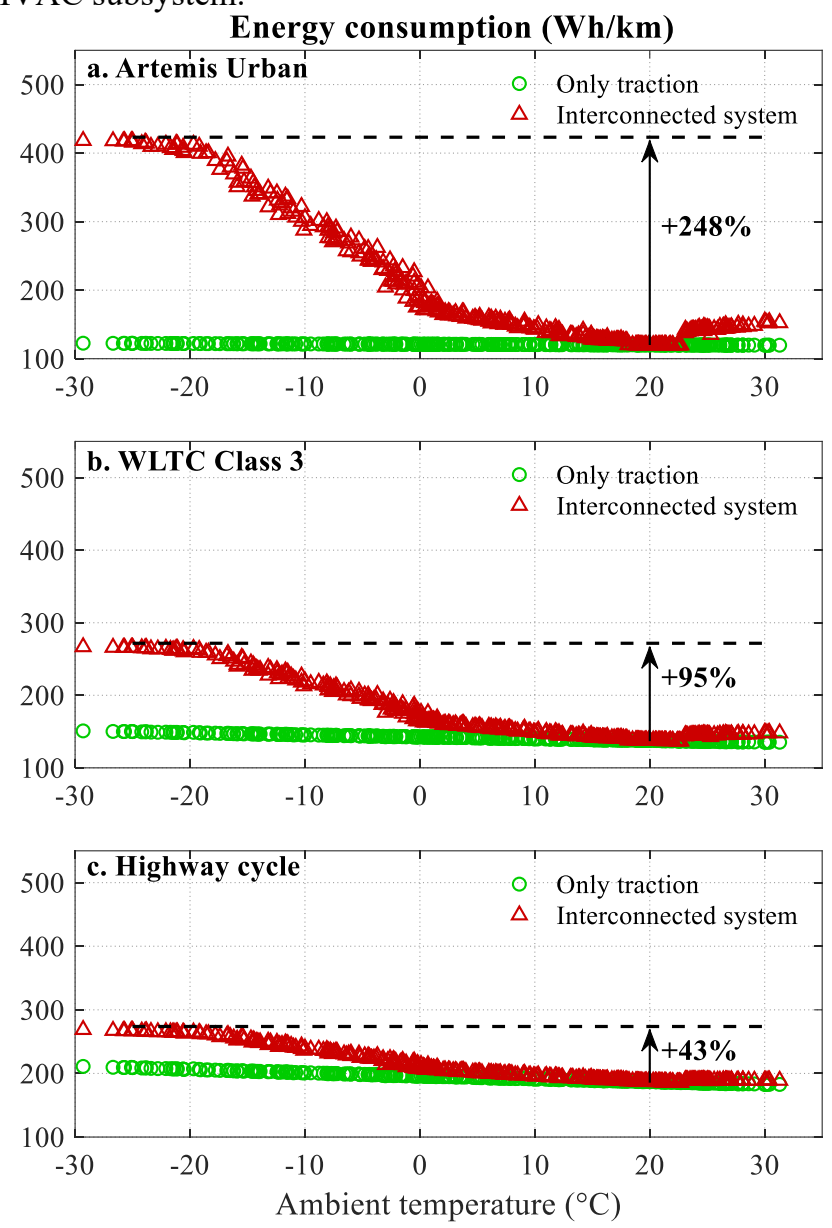

Fig. 13: Yearly variation of the energy consumption. a) Urban cycle. b) Extraurban cycle. c) Highway cycle.

Finally, Fig. 14 shows the monthly variation of the energy consumption by considering the 3 types of cycles and the interconnected system. The results show the very sharp contrast of the energy consumption between November and March (cold months), and that between April and October. Depending on the driving profile, the estimated energy consumption in winter ranges from 160 to $418 \mathrm{Wh} / \mathrm{km}$. In summer, it ranges from 120 to $200 \mathrm{Wh} / \mathrm{km}$.

\section{Energy consumption $(\mathrm{Wh} / \mathbf{k m})$}

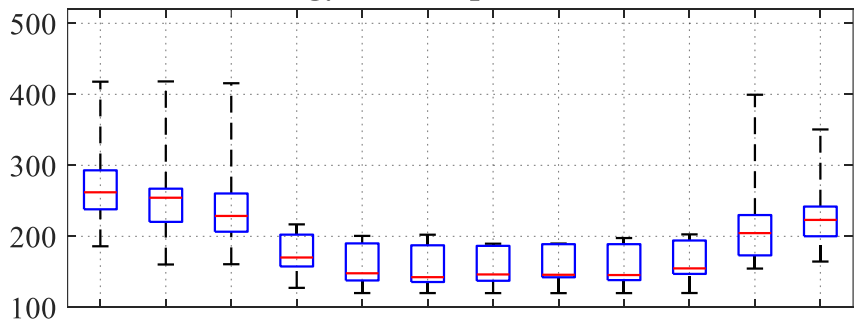

Jan Feb Mar Apr May Jun Jul Aug Sep Oct Nov Dec

Fig. 14: Monthly variation of the energy consumption of a BEV in Canada. 


\section{CONCLUSION}

This paper presents the interconnection of thermal and electromechanical models for the passenger cabin, the HVAC subsystem and the electric powertrain of a BEV. From the interconnected models, a flexible simulation of a BEV and its environment is developed thanks to a functional graphical description. The simulation is validated by experimental measurements taken on a real vehicle. The simulation then is used to estimate the contributions of the traction and HVAC subsystems to the overall energy consumption by considering 3 types of driving cycles. Finally, the yearly variation of the energy consumption is quantified under a wide range of real ambient conditions.

The results show the strong impact of thermal comfort on the overall energy consumption, especially for urban driving profiles in very cold conditions. Indeed, in extreme temperatures, the HVAC subsystem can even outweigh the traction subsystem in terms of energy consumption. Furthermore, the results show a yearly variation of the overall energy consumption of $248 \%$ in a Canadian climate (due to their very cold winters).

The next step is to include a thermal model of the battery, such as the one developed using EMR in [22]. Indeed, the battery thermal behavior is a key factor in the performance of the vehicle. In addition, a more complex model of the traction parts can be included, such as the effect of temperature on the wheel-road contact. Likewise, an advanced model of the HVAC subsystem could also consider the dehumidifier operation mode. The global model will enable more complete studies on BEVs at different climates, including the analysis of performance-improving guidelines (e.g., cabin and battery preheating). Finally, the presented models for the cabin and ventilation subsystems can also be adapted to thermal and hybrid vehicles. Future work could explore this adaptation by also considering an EMR-based model of an internal combustion engine and the use of waste heat, such as in [36].

\section{ACKNOWLEDGMENTS}

This paper has been achieved within the framework of the International Associated Laboratory "e-CAMPUS" of University of Lille (France) and University of Québec à TroisRivières (Canada), and with the funding of the Region "Hautsde-France". The experimental tests have been done using the "electricity \& Vehicles" platform of the L2EP of Lille, France.

\section{REFERENCES}

[1] B. Belgin, P. Magne, P. Malysz, Y. Yang, V. Pantelic, M. Preindl, A. Korobkine, W. Jiang, M. Lawford and A. Emadi, "Making the Case for Electrified Transportation," IEEE Trans. on Transport. Electrific., vol. 1, no. 1, pp. 4-17, 2015.

[2] M. Melliger, O. Van Vliet and H. Liimatainen, "Anxiety vs Reality Sufficiency of Battery Electric Vehicles Range in Switzerland and Finlad," Transportation Research Part D: Transport and Environment, vol. 65, pp. $101-115,2018$.

[3] Z. Zhang, J. Wang, X. Feng, L. Chang, Y. Chen and X. Wang, "The solutions to electric vehicle air conditioning systems: A review," Renewable and Sustainable Energy Reviews, vol. 91, pp. 443-463, 2018.

[4] G. Du, Y. Zuo, X. Zhang, L. Guo and N. Guo, "Heuristic Energy Management Strategy of Hybrid Electric Vehicle Based on Deep
Reinforcement Learning with Accelerated Gradient Optimization," IEEE Trans. on Transport. Electrific., vol. 7, no. 4, pp. 2194-2208, 2021.

[5] M. Ehsani, Y. Gao, S. Gay and A. Emadi, Modern Electric, Hybrid Electric and Fuel Cell Vehicles: Fundamentals, Theory and Design, 3rd Edition, Boca Raton, Florida, US: CRC Press, 2018.

[6] E. Ucer, I. Koyuncu, M. Kisacikoglu, M. Yavuz, A. Meintz and C. Rames, "Modeling and Analysis of a Fast Charging Station and Evaluation of Service Quality for Electric Vehicles," IEEE Trans. on Transport. Electrific., vol. 5, no. 1, pp. 215-225, 2019.

[7] M. Ebrahimi, M. Rastegar, M. Mohammadi, A. Palomino and M. Parvania, "Stochastic Charging Optimization of V2G-Capable PEVs: A Comprehensive Model for Battery Aging and Customer Service Quality," IEEE Trans. on Transport. Electrific., vol. 6, no. 3, pp. 10261034, 2020

[8] M. Jafari, A. Gauchia, S. Zhao, K. Zhang and L. Gauchia, "Electric Vehicle Battery Cycle Aging Evaluation in Real-World Daily Driving and Vehicle-to-Grid Services," IEEE Trans. on Transport. Electrific., vol. 4, no. 1, pp. 122-134, 2018.

[9] J. Jaguemont, L. Boulon, P. Venet, Y. Dubé and A. Sari, "Lithium-Ion Battery Aging Experiments at Subzero Temperatures and Model Development for Capacity Fade Estimation," IEEE Trans. on Veh. Tech., vol. 65, no. 6, pp. 4328-4343, 2016.

[10] J. Delos Reyes, R. Parsons and R. Hoemsen, "Winter Happens: The Effect of Ambient Temperature on the Travel Range of Electric Vehicles," IEEE Trans. on Veh. Tech., vol. 65, no. 6, pp. 4016 - 4022, June 2016.

[11] J. Zhang, Z. Wang, P. Liu and Z. Zhang, "Energy consumption analysis and prediction of electric vehicles based on real-world driving data," Applied Energy, vol. 275, p. 115408, 2020.

[12] Y. Al-Wreikat, C. Serrano and R. Sodré, "Effects of ambient temperature and trip characteristics on the energy consumption of an electric vehicle," Energy, vol. 238, 2022 [Early Access].

[13] A. Lajunen, Y. Yang and A. Emadi, "Review of Cabin Thermal Management for Electrified Passenger Vehicles," IEEE Trans. on Veh. Tech., vol. 69, no. 6, pp. 6025-6040, 2020.

[14] X. Ding, Z. Wang, L. Zhang and C. Wang, "Longitudinal Vehicle Speed Estimation for Four-Wheel-Independently-Actuated Electric Vehicles Based on Multi-Sensor Fusion," IEEE Trans. on Veh. Tech., vol. 69, no. 11, pp. 12797-12806, 2020.

[15] B. Guo and Y. Chen, "Robust Adaptative Fault-Tolerant Control of FourWheel Indepdently Actuated Electric Vehicles," IEEE Trans. on Industrial Informatics, vol. 18, no. 5, pp. 2882-2894, 2020.

[16] C. Fiori, K. Ahm and H. A. Rakha, "Power-based electric vehicle energy consumption model: Model development and validation," Applied Energy, vol. 168, pp. 257-268, 2016.

[17] A. Desreveaux, A. Bouscayrol, R. Trigui, E. Castex and J. Klein, "Impact of the Velocity Profile on Energy Consumption of Electric Vehicles," IEEE Trans. on Veh. Tech., vol. 68, no. 12, pp. 11420-11426, 2019.

[18] S. Scheubner, A. Thorgeirsson, M. Vaillant and F. Gauterin, "A Stochastic Range Estimation Algorithm for Electric Vehicles Using Traffic Phase Classification," IEEE Trans. on Veh. Tech., vol. 68, no. 7 , pp. 6414-6428, 2019.

[19] M. Ehsani, K. Singh, H. Bansal and R. Mehrjardi, "State of the Art and Trends in Electric and Hybrid Electric Vehicles," Proceedings of the IEEE, vol. 109, no. 6, pp. 967-984, 2021.

[20] Z. Yang, D. Patil and B. Fahimi, "Electrothermal Modeling of LithiumIon Batteries for Electric Vehicles," IEEE Trans. on Veh. Tech., vol. 68, no. 1, pp. 170-179, 2019.

[21] P. Tete, M. Gupta and S. Joshi, "Developments in battery thermal management system for electric vehicles: A technical review," Journal of Energy Sources, vol. 35, 2021.

[22] R. German, S. Shili, A. Desreveaux, A. Sari, P. Venet and A. Bouscayrol, "Dynamical Coupling of a Battery Electro-Thermal Model and the Traction Model of an EV for Driving Range Simulation," IEEE Trans. on Veh. Tech., vol. 68, no. 1, pp. 328-337, 2020.

[23] D. Marcos, F. Pino, C. Bordons and J. Guerra, "The development and validation of a thermal model for the cabin of a vehicle," Applied Thermal Engineering, vol. 66, pp. 646-656, 2014. 
[24] H. Lee, Y. Hwang, I. Song and K. Jang, "Transient thermal model of passenger car's cabin and implementation to saturation cycle with alternative working fluids," Energy, vol. 90, pp. 1859-1868, 2015.

[25] J. Wu, F. Jiang, H. Song, C. Liu and B. Lu, "Analysis and validation of transient thermal model for automobile cabin," Applied Thermal Engineering, vol. 122, pp. 91-102, 2017.

[26] B. Torregrosa, F. Bjurling, J. Coberán, F. Di Sciullo and J. Payá, "Transient thermal model of a vehicle's cabin validated under variable ambient conditions," Applied Thermal Engineering, vol. 75, pp. 45-53, 2015.

[27] ASHRAE Handbook - Fundamentals, Atlanta, GA, USA, 2017.

[28] Y. Çengel and M. Boles, Thermodynamics: An Engineering Approach, 8th ed., New York: McGraw-Hill Education, 2015.

[29] Q. Zhang, S. Stockar and M. Canova, "Energy-Optimal Control of an Automotive Air Conditioning System for Ancillary Load Reduction," IEEE Trans. on Control Systems Technology, vol. 24, no. 1, pp. 67-80, 2016.

[30] Y. Huang, A. Khajepour, F. Bagheri and M. Bahrami, "Modeling and optimal energy-saving control of automotive air-conditioning and refrigeration systems," Journal of Automobile Engineering, vol. 231, no. 3, pp. 291-309, 2017.

[31] S. Schaut and O. Sawodny, "Thermal Management for th Cabin of a Battery Electric Vehicle Considering Passengers' Comfort," IEEE Trans. on Control Systems Technology, vol. 28, no. 4, pp. 1476-1492, 2020.

[32] K. Y. Kim, S. C. Kim, and M. S. Kim, "Experimental Studies on the Heating Performance of the PTC Heater and Heat Pump Combined System in Fuel Cells and Electric Vehicles," International Journal of Automotive Technology, vol. 13, no. 6, pp. 971-977, 2012.

[33] F. Qin, Q. Xue, G. M. Albarracin, G. Zhang, H. Zou and C. Tian, "Experimental investigation on heating performance of heat pump for electric vehicles at $-20^{\circ} \mathrm{C}$ ambient temperature," Energy Conversion and Management, vol. 102, pp. 39-49, 2015.

[34] M. H. Park and S. C. Kim, "Heating Performance Characteristics of High-Voltage PTC Heater for an Electric Vehicle," Energies, vol. 10, no. 1494, 2017.

[35] J. Neubauer and E. Wood, "Thru-life impacts of driver aggression, climate, cabin thermal management, and battery thermal management on battery electric vehicle utility," Journal of Power Sources, vol. 259, pp. 262-275, 2014

[36] L. Horrein, A. Bouscayrol, Y. Cheng, C. Dumand, G. Colin and Y. Chamaillard, "Influence of the heating system on the fuel consumption of a hybrid electric vehicle," Energy Conversion and Management, vol. 129, pp. 250-261, 2016.

[37] A. Bouscayrol, J. P. Hautier and B. Lemaire Semail, "Graphic formalisms for the control of multi-physical energetic system: COG and EMR," in Systemic Design Methodologies for Electrical Energy Systems - Analysis, Synthesis and Management, ISTE \& Wiley, 2012.

[38] C. C. Chan, A. Bouscayrol and K. Chen, "Electric, Hybrid, and Fuel-Cell Vehicles: Architectures and Modeling," IEEE Trans. on Veh. Tech., vol. 59, no. 2, pp. 589-598, 2010.

[39] Renault, "Renault ZOE 2018 Datasheet," Renault, 2018.

[40] D. Ramsey, A. Bouscayrol, L. Boulon and A. Vaudrey, "Simulation of an electric vehicle to study the impact of cabin heating on the driving range," in IEEE VTC, Antwerp, Belgium, 2020.

[41] C. Dépature, W. Lhomme, A. Bouscayrol, L. Boulon, P. Sicard and T. Jokela, "Characterisation of the electric drive of EV: on-road vs off-road method," IET Electrical Systems in Transportation, vol. 7, no. 3, pp. 215222, 2017.

[42] Panda Project, "Report on the virtual testing of the BEV," European Comission, 2020. [Online]. Available: https://project-panda.eu.

[43] B. Heißing and M. Ersoy, "Driving Dynamics," in Chassis Handbook, Wiesbaden, Vieweg+Teubner Verlag, 2011, pp. 35 - 147.

[44] J. Duffie and W. Beckman, Solar Engineering of Thermal Processes, 4th ed., New Jersey, USA: John Wiley \& Sons, 2013.

[45] P. Berdahl and R. Fromberg, "The Thermal Radiance of Clear Skies," Solar Energy, vol. 29, no. 4, pp. 299-314, 1982.
[46] S. Algarni and D. Nutter, "Survey of Sky Effective Temperature Models Applicable to Building Envelope Radiant Heat Transfer," ASHRAE Transactions, vol. 121, no. 2, pp. 351-363, 2015.

[47] R. M. Rashid, "Thermal management of Vehicle Interior Temperature for Improvement of Fuel Economy," Master thesis at the University of Windsor, Ontario, 2018.

[48] D. Amelie, J. Augustine, K. Behrens, et al. , "Baseline Surface Radiation Network (BSRN): structure and data description (1992-2017)," Earth System Science Data, vol. 10, no. 3, pp. 1491-1501, 2018.

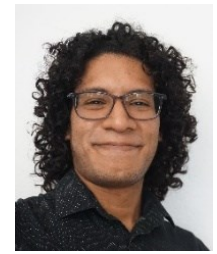

David Ramsey received his $\mathrm{PhD}$ degree in Electrical Engineering from the University of Lille and from the University of Quebec à Trois-Rivières, Canada, in 2021. He is currently a research engineer at the Laboratory of Electrical Engineering and Power Electronics (L2EP) of the University of Lille. His research interests include the modelling of electrified mobility.

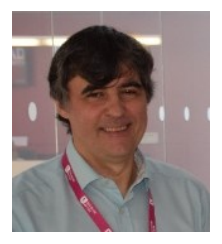

Alain Bouscayrol received the $\mathrm{PhD}$ degree in electrical engineering from the INP Toulouse, France, in 1995. From 1996 to 2005, he was an Associate Professor in the University of Lille, France, where he has been a professor since 2005. His research interests at the L2EP include graphical descriptions for control of electrified vehicles.

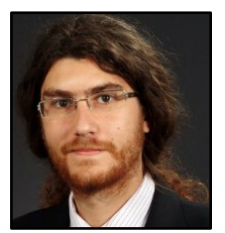

Loïc Boulon received his $\mathrm{PhD}$ degree in electrical engineering from the University of Franche-Comté, France. Since 2010, he has been a professor at Université du Québec à Trois-Rivières and a full professor since 2016. He works at the Hydrogen Research Institute, where he has been deputy director since 2019 .

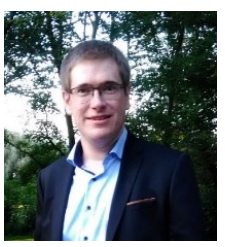

Anatole Desreveaux received his $\mathrm{PhD}$ degree in electrical engineering from the University of Lille, France, in 2020. From 2020 to 2021, he worked within the Panda H2020 project on the simulation of electrified vehicles at the Univ. Lille and L2EP, France. His research interests include the modelling and of electrified vehicles.

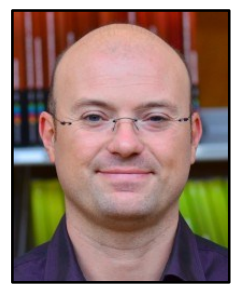

Alexandre Vaudrey received his $\mathrm{PhD}$ in Mechanical Engineering from the University of Franche-Comté, France, in 2009. Since 2014 to 2021, he was an associate professor at the Pontificia Universidad Católica del Perú (PUCP) in Lima, Peru. Since September 2021 is full time senior lecturer in physical sciences at the EIGSI La Rochelle, France." 